\title{
Successful Endoscopic Treatment of Refractory Postoperative Duodenocutaneous Fistula using Fibrin Sealant
}

\author{
Adam Dmitruk $^{1}$, Anna Pietrzak ${ }^{* 1,2}$, Maciej Rupinski ${ }^{1,2}$, Lukasz Zyskowski $^{1}$ and Tomasz Olesinski ${ }^{1}$ \\ ${ }^{1}$ Maria Sklodowska-Curie Memorial Cancer Center, Institute of Oncology, Warsaw, Poland \\ ${ }^{2}$ Department of Gastroenterology, Hepatology and Clinical Oncology, Medical Centre for Postgraduate Education, Warsaw, Poland
}

Received: 畊 July 02, 2018; Published: 制July 09, 2018

*Corresponding author: Anna Pietrzak, Roentgen 5 Str, 02-781 Warsaw, Poland

\section{Case Report}

Iatrogenic, postoperative enteroatmospheric fistulas remain difficult to manage but common problem after gastrointestinal surgery. Surgical revision, after failure of conservative treatment is not only partially efficient but also carries a high mortality risk, mainly due to patients' general condition and usually multiples comorbidities. Because of that alternative minimally invasive techniques are extensively studied, but unfortunately the data are still confounding [1,2]. We present a case of 38 - y.o. man with past history of nephrolithiasis, accidentally diagnosed with $30 \mathrm{~mm}$ gastrointestinal stromal tumour of the duodenum (Figures 1a-1c).

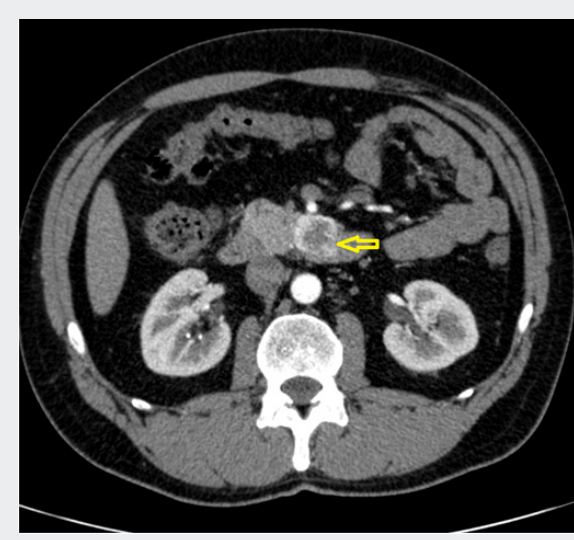

1a

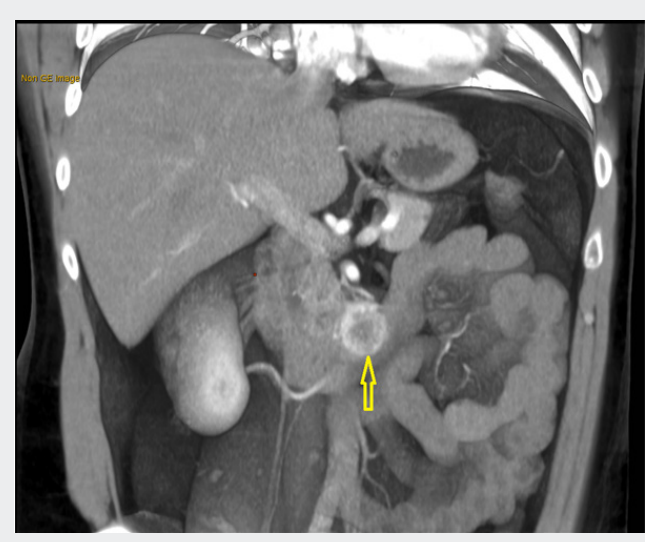

$1 b$

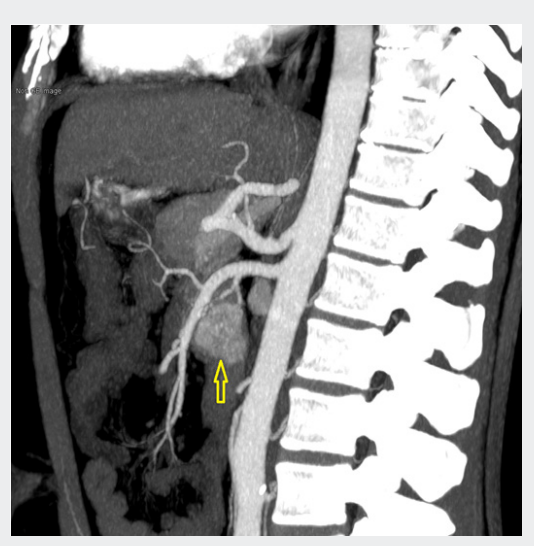

1c

Figure 1a: Contrast enhanced multidetector multiphase computed tomography of the abdomen and pelvis showing solid tumor $(\varnothing 30 \mathrm{~mm}$ ) between duodenum and pancreas (cross-section) (arrow).

Figure 1b: Contrast enhanced multidetector multiphase computed tomography of the abdomen and pelvis showing solid tumor (Ø $30 \mathrm{~mm}$ ) between duodenum and pancreas (anterior-posterior section) (arrow).

Figure 1c: Contrast enhanced multidetector multiphase computed tomography of the abdomen and pelvis showing solid tumor (Ø $30 \mathrm{~mm}$ ) between duodenum and pancreas (latteral-section) (arrow).

Tumour resection with end-to-end anastomosis of transversal duodenum was performed, but the procedure was complicated by massive intraabdominal bleeding leading to acute pancreatitis and finally to enterocutaneous fistula forming. In course of treatment, the patient required five reoperations with Roux-en-Y resection and sewing patch on the fistula's enteral orifice, but no one was efficient (Figures 2a\& 2b). To avoid another reoperation we decided to perform endoscopic fistula closure by injection fibrin glue (Tisseel, Baxter) into the internal opening (Figures 3a-3c). Procedure was performed via catheter using standard Olympus videoendoscope. We observed immediate fistula closing, and there were no early nor late complications related to the procedure. Patient was discharged after 67 days of hospital stay. After 11 months of follow-up patient remains cured (Figure 4). In conclusion, the fibrin sealant treatment is safer and much less invasive viable option, and it should be taken into account in selected cases [3].It appears that fistula closure is more efficient if performed from the internal opening. 


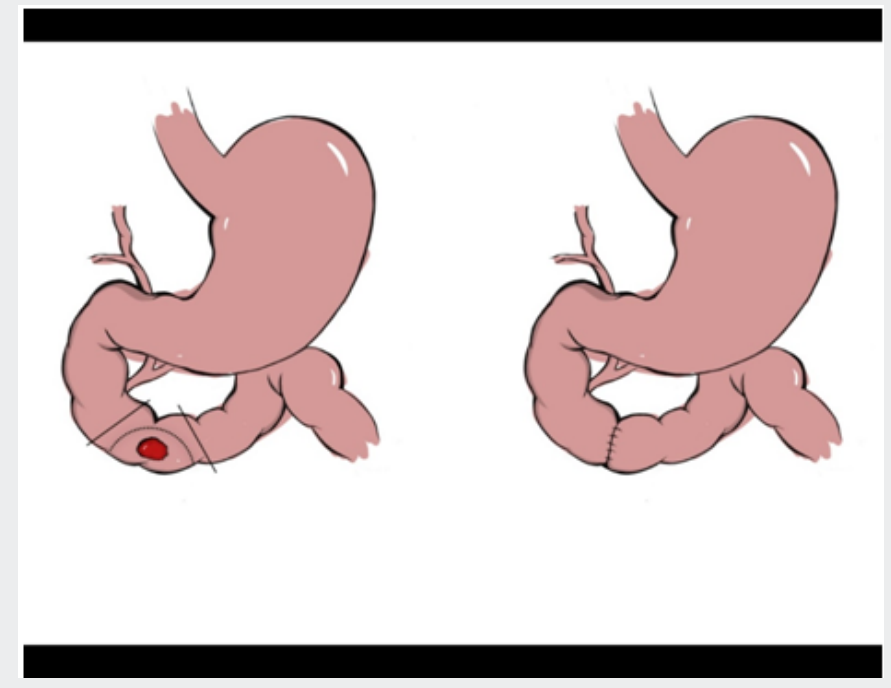

$2 a$

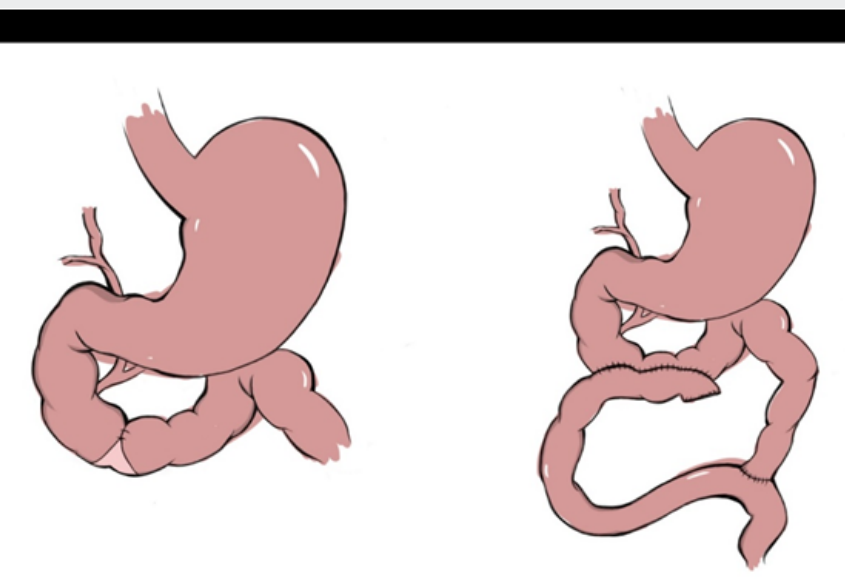

Figure 2a: Tumor of the duodenum and preformed resection scheme.

Figure 2b: Contrast enhanced multidetector multiphase computed tomography of the abdomen and pelvis showing solid tumor $(\varnothing 30 \mathrm{~mm})$ between duodenum and pancreas (anterior-posterior section) (arrow).

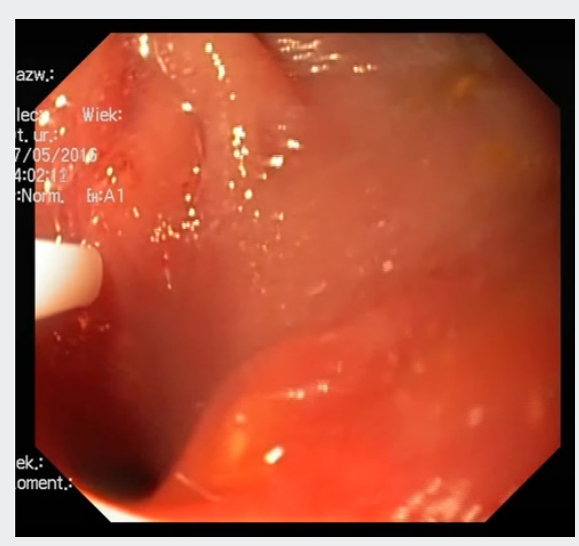

$3 \mathbf{a}$

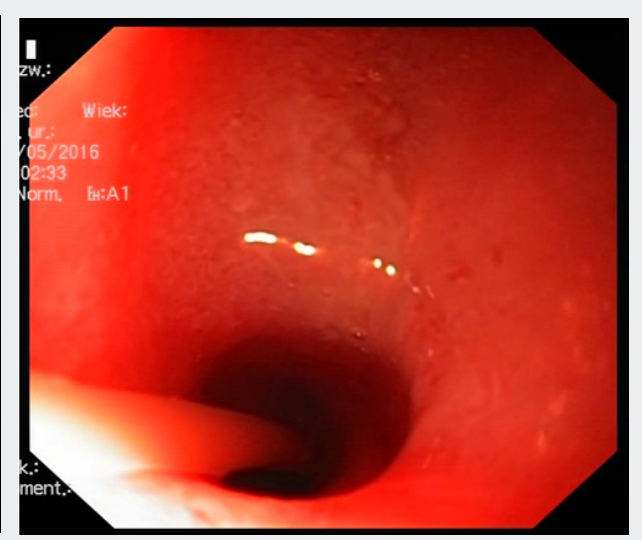

$3 b$

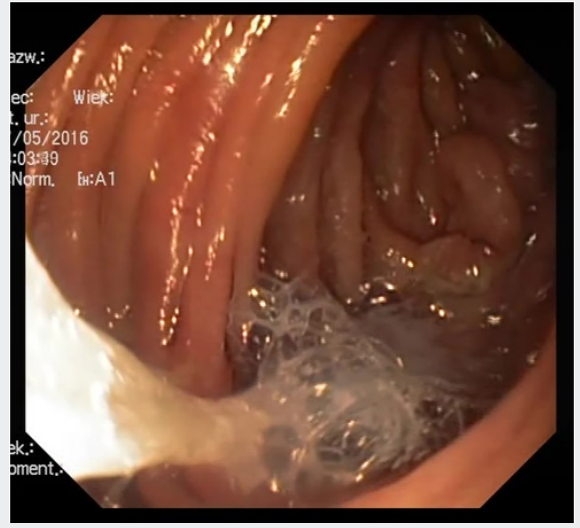

$3 c$

Figure 3a: Internal opening of duodenocutaneous fistula with catheter.

Figure 3b: Administration of fibrin sealant via catheter.

Figure 3c: Immediate fistula closing.

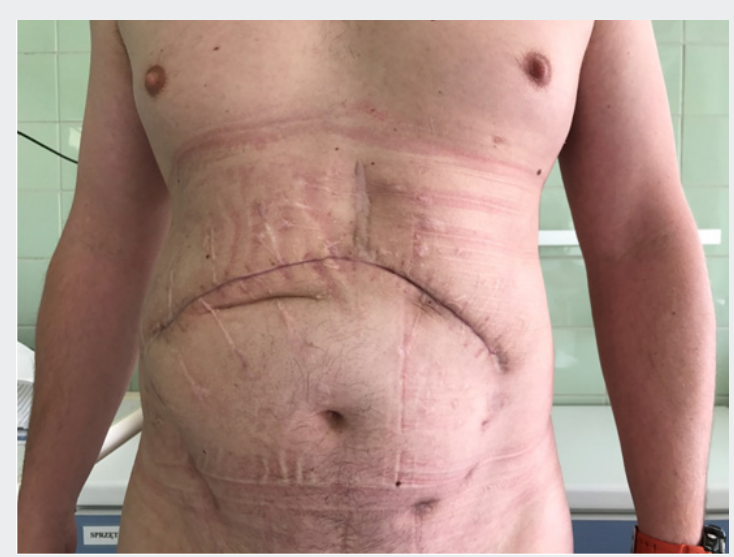

Figure 4: Abdominal wall after 11 months of follow-up. 


\section{References}

1. Galie K, Whitlow Cg (2006) Postoperative enterocutaneous fistula: when to reoperate and how to succeed. Clin Colon Rectal Surg 19(4): 237-246.

2. Kumar N, Larsen MC, Thompson CC (2014) Endoscopic management of gastrointestinal fistulae. Gastrenterol Hepatol 10(8): 495-452.

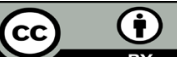

This work is licensed under Creative

Commons Attribution 4.0 License

To Submit Your Article Click Here:

Submit Article

DOI: $10.32474 /$ CTGH.2018.01.000109
3. Lippert E, Klebl FH, Schweller F (2011) Fibrin glue in the endoscopic treatment of fistulae and anastomotic leakages of the gastrointestinal tract. Int J Colorectal Dis 26(3): 303-311.

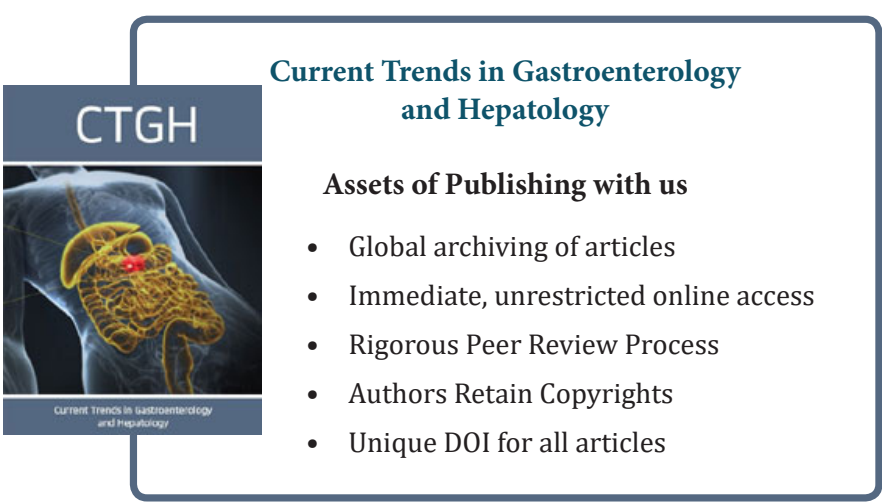

